\title{
Sustainability, stakeholders and business. Editorial
}

\author{
Alan Brown - Don E. Schultz - Claudio Baccarani \\ Gaetano M. Golinelli Corrado Gatti - Loredana Volpe
}

Over the past 20 years, there has been an increasing attention on the drivers of value in organizations. Both the strategic management literature and practice have remarked on the importance for managers to be aware of the impact of firm activities, products and services on both the external and internal environment and, more generally, on all firm stakeholders. The emergence of the notions of "sustainable development" and "sustainability" reflects a profound change in global thinking, which forces firms to move beyond trade-offs between business and society.

At the macro level, sustainable development advocates the interconnection among three inextricable principles, those of environmental protection, social equity and economic prosperity. These principles are reflected in the World Commission on Environment and The original definition of sustainable development as development that "meets the needs and aspirations of the present without compromising the ability of future generations to meet their own needs" (WCED, 1987, p. 43).

Indeed, sustainability advocates a more general principle of "respect" towards future generations related to the use of resources, which are not unlimited. This principle is clearly and effectively synthesized in a Native American's quote that clarifies how "we have not inherited the world from our fathers but borrowed from our sons".

At the organizational level, the notion of sustainable development has been translated into that of "corporate sustainability (CS)," which is based on the premise that a firm's success and health of communities around it are closely intermingled (Porter and Kramer, 2006; 2011). It is argued that, without integrating sustainability into business management, society will never achieve sustainable development as firms represent the productive resources of the economy (Bansal, 2002, p. 124). Hence, a sustainable firm is often qualified as one that undertakes "actions that appear to further some social good, beyond the interests of the firm and that which is required by law" (McWilliams and Siegel 2001, p. 117).

This notion has gained widespread acceptance in business practices and a prominent position within general management and strategic management literatures (cf. Atkinson, 2000; Bansal, 2002; Carroll, 1999; Cerin and Karlson, 2002; Dyllick and Hockerts, 2002; Gladwin et al., 1995a, 1995b; Hart, 1997; Jennings and Zandbergen, 1995; McWilliams and Siegel, 2001; Shrivastava, 1995).

However, "sustainability" can mean different things to different organizations. In particular, organizations might equate corporate sustainability to achieving environmental sustainability or see it as a compliance issue, a cost to be minimized or yet an opportunity to gain competitive advantage. Hence its implications for firms may vary. 
Sinergie Vol. 33, N. 96, 2015

In our viewpoint, "corporate sustainability" represents the turning point, which allows transforming the firm from a mere means for making profit into "the most creative human experiment that aims at improving life" (Csikszentmihaly, 2003). Embracing sustainability opens up new ways to create harmonious and consonant relationships between the firm and all its stakeholders, relationships based on a vision going beyond ourselves by looking for the highest shared benefit in order to build a better world. Such a vision interprets profit as the residual value derived from the production and diffusion of wellbeing created by the firm in a long-term action perspective in which corporate value and societal value will be aligned (KPMG International, 2014).

The goal of this special issue is to encourage, develop, and expand discussions regarding how sustainability is developed and maintained in business organizations with a particular emphasis on the application of various strategies, tactics, techniques and tools arising from research on the evolving approaches and concepts of sustainability.

The seven articles in this special issue address a diversity of topics, which show the multi-faceted and complex nature of sustainability. The papers cluster into five thematic groups: (i) stakeholders strategy and sustainability; (ii) sustainable innovation and business; (iii) sustainability and risk management; (iv) cooperative strategies and network dynamics induced by sustainability and their evolution; (v) sustainability communication.

Next, we provide a summary of each of these contributions.

\section{Articles}

Starting from the first group (i.e. stakeholders strategy and sustainability), in their article titled "Sustainability and stakeholder approach in Olivetti from 1943 to 1960: a lesson from the past", Sciarelli and Tani use the interpretative framework proposed in the literature by Carroll (1979) to analyze the entrepreneurial choices made by Adriano Olivetti. Based on theoretical antecedents from the Stakeholder Management Theory (Freeman, 1989) and by linking - methodologically - the pyramid of Corporate Social Responsibility defined by Carroll (1979) to the stakeholder management approach proposed by Goodpaster (1991), the authors elaborate on how managing relationships with stakeholders can enhance the company's value creation process, in terms of both its economic dimension and social dimension. Some important points emerge from this contribution. First, corporate sustainability starts from the top and implies that top managers put effort in integrating the various complementary stakeholders' interests. Second, by adopting a multi-fiduciary approach to reduce potential and latent conflicts, the sustainable firm is also a profitable firm. As the authors comment: "The drive towards innovation was considered as a way to make the employees conditions' better...At the same time it lead Olivetti to increase its profits by keeping its products ahead of those of the competitors, as a main element to satisfy economic responsibilities towards both the employees and the shareholders". 
In terms of the second group (i.e. sustainable innovation and business), Tencati and Pogutz emphasize the need to introduce a new conceptual framework in order to identify key drivers of change necessary to embracing sustainability, and to overcome the limits of the corporate greening approach. Although the authors seem to refer to a mostly ecological view of sustainability, they address four relevant areas of intervention: creating distributed production units and internal processes; designing sustainable products and services; developing sustainable supply chains; deploying radically new business models. These interventions should pave the way to a "new paradigm" grounded on different forms of innovation and on the implementation of shared and participative strategies among different players able to promote the diffusion of innovative practices and technologies.

Commenting specifically from a risk management perspective, in their article titled "Managing risks in sustainable supply chains," Christopher and Gaudenzi discuss the emerging challenges that face modern supply chains from the perspective of sustainability. A couple of relevant issues emerge from their paper. On the one hand, the authors attempt to specify what sustainability means in terms of a firm's supply chain: sustainability is "related to "green" - environmentally responsible - supply chains that eliminate waste, reduce pollution and contribute in a positive manner to improving the quality of the environment through eco-friendly processes, subassemblies and finished goods" (p. 3). On the other hand, they elaborate on the relationship between sustainability and risk. In decomposing the general risk management literature, the authors differentiate between "sustainability risk management" and the categorization of "risks in sustainable supply chains", and argue that Supply Chain Management offers opportunities to economize on costs and mitigate risk to the extent that they are part of a more general approach to corporate sustainability. Such an approach includes for instance green product design and packaging specifications that minimize waste, extend life, utilize recycled content and increase recyclability and other activities along the supply chain whereby "being green" and good on reducing risks does eventually pay off the firm.

With reference to the fourth thematic group (i.e. cooperative strategies and network dynamics induced by sustainability and their evolution), De Chiara introduces a relational perspective on sustainability by exploring the opportunity to implement a steered collaboration between firms and other public and private actors, which allows facing the complexity of issues related to embracing sustainability. Such opportunity comes through the implementation of a collective impact approach, defined as a "type of collaboration which solicits a separate organization(s) with staff, a specific set of skills and a structured process to create a common agenda, shared tools, a continuous communication and mutually reinforcing activities among all members" (pp. 5-6). By analyzing the case of Agro Caleno, the authors eventually conclude that, in the face of the complex problems (such as environmental pollution) brought on the scene by sustainability, cross-sectoral public and private partnerships should be placed within a more general approach which allows leveraging the relationships between different stakeholders and the progress towards shared goals. 
Sinergie Vol. 33, N. 96, 2015

This fourth thematic group combines two other contributions, which focus on a network perspective in addressing how firms seek to become sustainable. Such papers place the debate on sustainability within two distinct sectoral backgrounds. In particular, in their article titled "Sustainability through energy efficiency: An Italian perspective," Testa and Vigolo investigate how Italian firms - and Small and Medium Enterprises (SMEs) above all - might identify possible solutions to overcome barriers to energy efficiency, in terms of technology investments and energy management. Their conceptual work thus explicitly relates being sustainable to energy efficiency, or rather to overcoming both the internal barriers (related to the firm) and external barriers (related to the regulatory environment), which prevent SMEs to accomplish energy efficiency. Interestingly, the authors advance some solutions to the energy efficiency gap for Italian SMEs, all of them leading to stress the importance of collaboration between firms in overcoming major economic/financial and informational barriers to efficiency. The solutions proposed also highlight the role of institutional counterparts in creating an energy efficiency culture and in raising awareness. Under this network perspective, the action of firms achieving higher energy efficiency positively cascades on the environment (through the increase of renewable sources) and on society (since decentralization of production would increase competition and reduce energy bills for households).

Martini and Buffa also show a network view of sustainability but with reference to a different sectoral framework, i.e. sustainability in tourism. More specifically, the authors suggest social network analysis (SNA) as an appropriate method to explain the dynamics of interpersonal relationships in tourist areas. To this end, they focus on the sustainable firm operating in tourism as one that "tries to balance the economic returns of tourism with the conservation of the non-renewable resources consumed by the tourist industry" (p. 2). Given such definition, in the authors' opinion, the analysis of corporate sustainability in the tourism sector calls for investigating the network of relationships between the various actors, and understanding the nature and strength of their connections. More specifically, according to the authors, when referred to tourism, sustainability calls for a different territorial governance system, which should provide direction for both organizational and institutional behaviours, and become an integral part of the management of a territory. Framing sustainability through the social network analysis lens thus allows identifying the nodes within a community that are capable of conveying information, influencing behaviours and decisionmaking, governing effectively and taking political action in order to foster participative governance in accordance with sustainability principles.

In terms of the fifth group of issues (i.e. sustainability communication), Eagle, Low and Vandommele review the literature on social marketing based on the premise that a focus on sustainability requires behaviour change from individuals and communities. The authors detail the complexity of factors, which might either positively or negatively impact on communication of the need for behaviour change, which is related to embracing sustainability. They eventually call for a multidisciplinary, 
interdisciplinary and transdisciplinary research agenda, seeking input from different disciplines and leveraging synergistic effects in applying multiple research approaches and analytical methods to the interpretation of findings. A multidisciplinary, interdisciplinary and transdisciplinary approach allows

developing shared conceptual frameworks that integrate and transcend individual disciplines.

\section{Conclusions}

Each of the thought-provoking articles included in this special issue indicates that the field of corporate sustainability has made important progress in terms of bridging different theoretical perspectives and methodological approaches. However, much progress still remains to be achieved. In particular, future research could address additional key issues that have the potential to provide useful, specific, and actionable suggestions in sustainability research but have not yet been addressed in the existing literature.

Concerning this, it is interesting to notice how some areas of research on corporate sustainability still appear somehow left under-attended. These areas can be mostly referred to two domains of interest. On the one hand, the relationship between the sustainability notion and the theory of the firm still needs further inquiry. On the other hand, the need emerges to bridge theory and business practice in explaining the transition of both the academic world and the professional world towards sustainability. Under this viewpoint, a merely eco-centric view of sustainability, although essential, does not seem sufficient to transform the competitive landscape and stimulate business organizations to radically change their current ways to think about products, processes, cooperative relationships, technologies and business models.

Conversely, placing sustainability within a higher-level systemic approach might provide the ideal setting for theory building and a critical research agenda. Such an agenda leads to thinking of sustainability as a true "management philosophy" which calls for renovating the traditional profit culture in firm management and focuses on the importance of some key and interdependent pillars which qualify the "sustainable firm": top management commitment toward sustainability principles, the role of sustainability networks in defining the guidelines of value creation and exerting pressures on the firm and its governance to adopt the new rules of sustainable firm behaviour; the drivers of consonance and competitiveness revisited under a three-fold (economic, social and ecological) light; finally, the need for a new and interdependent governance of the firm and its multiple stakeholders. When incorporated into a more systemic approach, all the mentioned factors naturally bring sustainability beyond the merely ecological and philanthropic circuits, and place it within a real "corporate" domain. Under such an approach, the sustainable firm becomes a fundamental component of a network of relations and interdependencies among a number of entities that, although remaining independent from each other, yet cooperate to a shared value creation project. 
Sinergie Vol. 33, N. 96, 2015

The authors in this special issue have made a considerable effort towards understanding the new sustainability philosophy. They address some relevant concerns about how sustainability relates to firm behaviour and survival by focusing on relevant yet specific issues of ecological efficiency, supply chain management, risk management, and communication. However, to look at sustainability from a corporate and more systemic perspective allows noticing that, on the one hand, there is little evidence to draw definitive conclusions, whereas on the other it is enough clear that we need to know more. Many questions concerning sustainability have already been addressed but many others still remain that ask for a mix of (a) a critical debate on sustainability to sort out the inherent limitations and the potential of the current approaches, and (b) the capacity to go further in the current debate and integrate multiple perspectives in a more systematic and systemic approach.

With the concept of sustainability still defined in multiple and distinct ways, we believe that the most relevant contributions to this nascent field should come from scholars placing additional effort on theory building. In this context, the articles in this special issues pave the way to achieve such progress but also emphasize that more qualitative and quantitative testing would also be helpful for areas such as "the business case" for sustainability, the voluntary nature of the initiatives that firms undertake in its name in contrast to the formal regulatory mechanisms historically employed to govern firms, and last but not least, the fact that integration of sustainability principles in firm management still has many doubters and critiques. We hope this special issue will serve as a catalyst for further integrative research efforts in the field of sustainability. We believe that such integration will help fill not only the gaps in current literature but also, and more importantly, to bridge the much lamented science-practice gap in management.

\section{References}

ATKINSON G. (2000), "Measuring corporate sustainability", Journal of Environmental Planning and Management, vol. 43, n. 2, pp. 235-252.

BANSAL P. (2002), "The corporate challenges of sustainable development", Academy of Management Executive, vol. 16, n. 2, pp. 122-131.

CARROLL A. (1999), "Corporate social responsibility: evolution of a definitional construct", Business and Society, vol. 38, n. 3, pp. 268-295.

CERIN P., KARLSON L. (2002), "Business incentives for sustainability: a property rights approach”, Ecological Economics, vol. 40, n. 1, pp. 13-22.

CSIKSZENTMIHALY M. (2003), Good Business. Leadership, Flow and the Making of Meaning, Viking Penguin, New York, pp. 187-198.

DYLLICK T., HOCKERTS K. (2002), "Beyond the business case for corporate sustainability", Business Strategy and the Environment, vol. 11, n. 2, pp.130-141.

GLADWIN T., KENNELLY J., KRAUSE T-S. (1995a), "Shifting paradigms for sustainable development: implications for management theory and research", Academy of Management Review, vol. 20, n. 4, pp. 874-907. 
GLADWIN T., KRAUSE T.S., KENNELLY J. (1995b), "Beyond eco-efficiency: Alan Brown towards socially sustainable business", Sustainable Development 3, n. April, Claudio Baccarani pp. 35-43.

Gaetano M. Golinell

Corrado Gatti

Loredana Volpe

HART S. (1997), "Beyond greening: strategies for a sustainable world", Harvard Sustainability,

Business Review, vol. 75, n. 1, pp. 66-76.

stakeholders and business.

Editorial

JENNINGS P.D., ZANDBERGEN P.A. (1995), "Ecologically sustainable organizations: an institutional approach", Academy of Management Review, vol. 20, n. 4, pp. 1015-1052.

KPMG INTERNATIONAL (2014), A New Vision of Value, Connecting corporate and societal value creation, KPMG.com, pp. 4-38.

MCWILLIAMS A., SIEGEL D. (2000), "Corporate social responsibility and financial performance: correlation or misspecification?", Strategic Management Journal, vol. 21, n. 5, pp. 603-609.

PORTER M.E., KRAMER M.R. (2011), "Creating shared value", Harvard Business Review, vol. 89, n. 1/2, pp. 62-77.

PORTER M.E., KRAMER M.R. (2006), "The link between competitive advantage and corporate social responsibility", Harvard business review, vol. 84, n. 12, pp. 78-92.

SHRIVASTAVA P. (1995), "The role of corporations in achieving ecological sustainability”, Academy of Management Review, vol. 20, n. 4, pp. 936-960.

\section{Academic or professional position and contacts}

Alan Brown (Guest Editor)

Full Professor

Edith Cowan University, Perth, Australia

e-mail: alan.brown@ecu.edu.au

Don E. Schultz (Guest Editor)

Professor Emeritus-in-Service

Northwestern University, Evanston, IL, USA

e-mail: dschultz@northwestern.edu

\section{Claudio Baccarani}

Full Professor of Management

University of Verona, Italy

e-mail: claudio.baccarani@univr.it

\section{Gaetano M. Golinelli}

Professor Emeritus of Management Sapienza University of Roma, Italy e-mail: gaetano.golinelli@uniroma1.it

\section{Corrado Gatti}

Full Professor of Management

Sapienza University of Roma, Italy

e-mail: corrado.gatti@uniroma1.it

\section{Loredana Volpe}

PhD of Management

Sapienza University of Roma, Italy

e-mail: loredana.volpe@uniroma.it

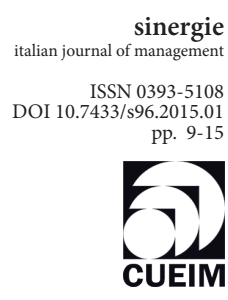

